\title{
What Puts Medical Students off Psychiatry?
}

JAN SCOTT, Lecturer in Psychiatry, Department of Psychological Medicine, University of Newcastle upon Tyne

At present about $4 \%$ of doctors opt for a career in psychiatry. ${ }^{1}$ Between 1974 and 1977 almost a quarter of the consultant posts in general psychiatry remained unfilled; in 1981 there were no less than 220 unfilled consultant vacancies. ${ }^{2}$ This shortage is regarded by many as representing a deficiency in quality as much as quantity of applicants. ${ }^{3}$ If the consultant grades are expanded in the future to the levels suggested by the Short Report these problems are likely to increase rather than decrease, unless recruitment into the speciality is enhanced.

Over the last 10 years much has been written on ways of improving undergraduate teaching in psychiatry and ultimately of attracting more medical students into the speciality but, as yet, changes in the teaching courses, more 'socially aware' students and more professorial units have not produced a significant increase in the numbers opting for psychiatry. It therefore seemed appropriate to try to find out why the graduates of one British medical school are still reluctant to pursue a career in this speciality. In order to obtain this information a brief questionnaire was sent to each final year student at Newcastle University Medical School immediately after their last undergraduate attachment in psychiatry.

\section{Survey and results}

The survey set out to explore the attitudes and opinions of the medical students towards psychiatry in general rather than examine any specific criticisms of the teaching in Newcastle. Their views were also sought on factors which might make the speciality particularly attractive or unattractive to them. Questions in the survey fell into two categories-those aimed at basic data collection (c.g. age, sex, career preferences, etc.), and a set of more 'openended' questions which attempted to gain greater insight into the students' views and attitudes (e.g. whether and how the experience of psychiatry had improved or worsened their opinion of the subject, particular criticisms they had of the speciality, etc.).

Eighty-seven completed questionnaires were returned out of a total of 123 students. Thus the sample comprised $70.7 \%$ of the year (the high return was brought about by publicising the study and personally reminding students to return the forms). The average age of the sample was 23.7 years and included four mature students (all male). Some students still did not have clearly defined career plans but when questioned about their most probable choice 17 students $(19.5 \%)$ were interested in general surgery, 18 students $(20.7 \%)$ general medicine and 38 students $(43.7 \%)$ general practice. Those considering careers in other specialities or as yet undecided accounted for a further $11.5 \%$ (10 students). Four students ( $4.5 \%)$ were interested in a career in psychiatry; one was female and three were male, of whom one was a mature student.

Interestingly, the three younger students were particularly definite about their career plans and had been keen on a career in psychiatry virtually since entering medical school. When asked if they would consider psychiatry as a second choice career option 11 students $(12.6 \%)$ answered yes. Eight of these students were drawn from the group choosing general practice as their first option and two were from the general medicine group.

Virtually all the students acknowledged the importance of psycho-social factors in any patient suffering from physical illness, but only $10(11.5 \%)$ felt that their career choice was determined specifically by an interest in the 'psycho-social' or 'social' aspects of medicine. Of this group, only three chose psychiatry as their first option, the other students intended to follow a career in general practice, putting psychiatry as second choice on six out of seven occasions.

The students were then asked particularly about their attitudes towards psychiatry and about any difference in these before and after their clinical experience of the speciality. A surprisingly large number (66 students) seemed to find their psychiatry attachment enjoyable, and over half the group (47 students) felt that their overall impression of psychiatry had improved, only seven had a worse opinion of the speciality than before. There were many criticisms, however, which can be divided into four broad (somewhat overlapping) categories: Opinions about the speciality in general and its relationship to medicine; opinions about the available treatments; opinions about psychiatrists; opinions about the patients.

(1) There were several recurring themes which seemed to focus particularly on the view that psychiatry lacked objectivity and was unscientific $(35.5 \% ; 31$ students) or did not make enough use of medical techniques or skills (17.2\%). Several regarded the speciality as too confusing (six students) and three students felt that psychiatry should not be regarded as a branch of medicine at all. Two others stated that they would not consider working in the speciality because conditions in large mental hospitals were too depressing'.

(2) Twenty-one students $(24 \cdot 1 \%)$ felt that the treatments were either too limited or ineffective and over half of these (13.8\%) expressed disappointment at the apparent lack of improvement shown by patients they had been involved with during their attachments. Others (five students) related this is some way to the lack of scientific sophistication of the speciality. 
(3) Psychiatrists themselves also came in for criticism. Some students have a rather poor image of psychiatrists similar to that portrayed by our less sympathetic nonpsychiatric colleagues. Occasional comments such as 'Psychiatrists are emotionally unstable' occurred on $4 \%$ of questionnaires and eight students $(9 \cdot 2 \%)$ stated that psychiatrists were 'second rate' doctors, and some went on to suggest that they chose the speciality either as a 'soft option' or because they just could not 'compete' in the more popular specialities.

(4) Two students felt that they simply did not like the patient population they were expected to deal with and one other stated he felt that the patients were too prone to violence.

Only $48 \%$ (42 students) wrote any comments when asked about aspects of the subject that might attract them to the speciality. Most students (18) concentrated on the 'psycho-social' or 'social' aspects of medicine and the idea that each patient was treated as an individual. However, these students also felt that these interests were readily met by a career in general practice, and most (15) saw this as a more attractive option. Other factors considered important were improved job prospects (6), better working hours (5) and the openings for part-time work (3), but these positive features did not seem to be sufficiently attractive to overcome the more negative aspects of the speciality.

Twenty students commented on how they thought recruitment into psychiatry might be improved. Fifteen students $(17.2 \%)$ put forward the suggestion that they should have an increased exposure to liaison psychiatry in their training so that they might maintain a more active interest in the speciality during their other clinical attachments. In addition, nine students felt they did not have any real knowledge of postgraduate training or the varied possibilities that a career in psychiatry might offer. They suggested that this information might improve recruitment in the long term.

\footnotetext{
Comment

It appears that many of the views put forward by these students reflect those in the previously published literature. ${ }^{4}$ Indeed, this seems to be true despite the many changes that have been made in the teaching of the speciality since those earlier studies. Brook ${ }^{1}$ has stated that the enthusiasm of the teachers and the model of psychiatry put forward may have an important effect on an undergraduate's attitude towards the speciality. Thus some of the comments made might be seen to relate more directly to the teaching of psychiatry in Newcastle upon Tyne. However, the output of psychiatrists from this medical school in the past decade does seem to reflect the national figures fairly accurately and the teaching methods are not seen as significantly better or worse than those employed in other teaching centres. The ideas and views of the students in this sample are therefore unlikely to differ dramatically from those of the undergraduates at other medical schools in Britain.
}

Whilst an attachment in psychiatry did seem to improve the students' attitude towards the speciality, it did not seem to increase the attractiveness of psychiatry as a first choice career option. For the students in this sample who intended to pursue a career in psychiatry their decision was not made on the basis of their undergraduate experience alone but on a long term commitment to the speciality. Also, they had received little encouragement or advice from their tutors or teachers. Indeed one student stated that his tutor had tried to dissuade him from his choice on the grounds that he was "capable of better things'. For some potential recruits the stereotype portrayed by their non-psychiatric teachers may act as a deterrent and they may then be drawn towards other, more prestigious specialities. It is particularly noteworthy that, as Brook ${ }^{1}$ has suggested, the career pull from general practice attracts many of the students who express an interest in the 'social' or 'psycho-social' aspects of medicine. Additional deterrents for a smaller number would appear to be the working conditions or quite simply a dislike of the patient population they are expected to deal with.

These factors however seem to be almost negligible compared with the students' opinions of the speciality itself and its available treatments. From the undergraduate viewpoint psychiatry lacks a proper scientific basis and is too inexact. Learning basic textbook information or eliciting a check-list of symptoms does not allow mastery of this complex subject and laboratory confirmation of a diagnosis is rarely possible. This contrasts sharply with their experience of other branches of hospital medicine which are geared towards quick, precise diagnoses and treatment of physical illnesses supported by objective investigations. The students are taught that the use of these sophisticated scientific tests systematises good clinical practice; thus they believe that psychiatry is not only different but inferior. Unfortunately, psychiatrists have been only too aware of the short-comings of their speciality and have been guilty of not challenging these views. In addition, the time-scale of any recovery is longer, leaving the students believing few treatments are either helpful or effective.

Whilst an increase in the length of the undergraduate attachments might help it would be difficult to effect, and perhaps it is the students' experience of psychiatry that needs to be revised.

Firstly, it would be sensible to heed the students' suggestions about liaison psychiatry, particularly in view of the NIMH study reporting a $40 \%$ increase in recruitment to the speciality from those medical schools where liaison work is the main focus of teaching. ${ }^{1}$ The additional advantage of this is the emphasis on psychiatry as part of general medicine. Psychiatrists could also be more active in helping students extend their experience of the speciality by increasing the number of projects they offer to students embarking on a Bachelor of Medical Science degree course and by encouraging others to become involved in supervised psychology or psychiatry projects during their clinical training. Alternatively, students could be given the opportunity to engage in supervised out-patient psycho- 
therapy as described by Garner." Lastly, perhaps more attractive student electives could be devised at psychiatric establishments both at home and abroad. Interestingly, in Newcastle, Mental Health Foundation grants have been made available to a number of students and, following electives in psychiatry, all have pursued a career in the speciality.

Many developed their interest in psychiatry at a later stage and recent schemes such as the pre-registration psychiatry posts in Sheffield, ${ }^{6}$ have important implications particularly as Parkhouse \& Dartun ${ }^{7}$ have suggested that after extended exposure to the speciality the drop-out rate is low.

In the long term, psychiatrists obviously have a key role in enhancing recruitment. If the attitudinal shift shown by many of the students is maintained in the future it may be easier for some potential trainees to enter the speciality. However, this will not happen unless psychiatrists commit themselves to active and enthusiastic recruitment. Ultimately, this commitment must be matched by an equal determination to extend our understanding of the disorders we treat and to receive adequate support in these endeavours. It is perhaps still pertinent to consider the comment of Ellis, ${ }^{8}$ made over 20 years ago- The fact that
$40 \%$ of British hospital beds are occupied by psychiatric patients will never lead students to be interested in psychiatry as will some therapeutic advance which empties these beds'.

REFERENCES

'Brook, P. (1983) Who's for psychiatry? United Kingdom medical schools and career choice of psychiatry, 1961-75. British Journal of Psychiatry, 142, 361-365.

${ }^{2}$ Kartun, D. (1983) Psychiatry in anguish. World Medicine, Jan. $22,46$.

${ }^{3}$ MorRes, P. (1982) The poor image of psychiatrists. World Medicine, Feb. 6, 101-103.

4CREED, F. (1979) Who Puts Medical Students Off Psychiatry? Welwyn Garden City: Smith Kline \& French Publications.

${ }^{5}$ Garner, P. (1981) Psychotherapy: Experience as a medical student. British Medical Journal, 282, 797.

${ }^{6}$ Seager, C. P. (1985) Pre-registration house officer posts in psychiatry. Bulletin of the Royal College of Psychiatrists, 9, $141-142$.

'PARXrouse, J. M. \& Dartun, R. A. (1979) Training in the hospital specialities in Britain in 1975. British Medical Journal, 1, 670.

${ }^{8}$ EuLs, J. (1963) The teaching of psychiatry. British Medical Journal,. 2, 585-588.

\section{Second Annual Meeting of the Society for Psychotherapy Research}

Graeme McGrath, Lecturer in Psychiatry, University Hospital of South Manchester and

StEVE ReILly, Senior Registrar in Psychotherapy, Regional Psychotherapy Unit, Gaskell House, Swinton Grove, Manchester

The United Kingdom branch of the Society for Psychotherapy Research SPR(UK) held its second annual meeting at Ravenscar in North Yorkshire in April 1985. The setting, as in 1984, was a hotel high on a cliff overlooking Robin Hood's Bay, where conference members with a few minutes to spare could walk in the clifftop gardens or attempt the arduous climb down to the beach. No one took advantage of the golf course this year, nor apparently was anyone hardy enough to swim in the open-air pool!

The meeting was divided into six plenary sessions each with a common theme and three smaller workshops. Presentations were of a uniformly high standard and ranged from reports of small-scale research projects carried out by individuals in the course of everyday clinical work to large-scale projects with elaborate experimental design and teams of investigators. The message was ciear: valuable psychotherapy research can be and is being done in busy NHS settings and well-endowed academic institutions alike, and moreover is being carried out by psychotherapists from a variety of professional backgrounds including psychiatry, clinical psychology and social work; a combination guaranteed to provide a fertile substrate for the generation and testing of new ideas.
It is not possible to discuss psychotherapy research for long without considering the related issues of process and outcome, and this was the theme of the opening session, devoted to work derived from the Sheffield Psychotherapy Research Project. David Shapiro discussed this comparative study of prescriptive versus exploratory psychotherapy using a sophisticated crossover design in which therapist variables were controlled by having the same therapist deliver both modes of therapy to the same patient. This work shows that both exploratory and prescriptive modes of therapy are effective and also that the outcome differs depending on the order in which treatments are given. This is clearly an important finding when considering studies which seem to show little difference in effect between different treatments. Shapiro was the first of several presenters to point out that when considering service delivery and priorities in research the issue of cost effectiveness must be taken into account.

Jenny Firth described some of the techniques used in the research and gave clinical examples. Bill Styles, using the same pool of patients, described his work on the immediate impact of individual sessions as judged by patients and therapists. Session impact is a separate concept from both 